www.jmscr.igmpublication.org

Impact Factor (SJIF): 6.379

Index Copernicus Value: 71.58

ISSN (e)-2347-176x ISSN (p) 2455-0450

crossrefDOI: https://dx.doi.org/10.18535/jmscr/v6i7.43

Journal Of Medical Science And Clinical Research

\title{
A Study of Echocardiographic Evaluation of Diastolic Function in Type 2 Diabetes Mellitus patients without Cardiovascular Risk Factors
}

\author{
Authors \\ Dr Yallappa Reddy H M', Dr Savesh Roshan ${ }^{2}$ \\ ${ }^{1}$ Assistant Professor, Department of General Medicine, S.S. Institute of Medical Sciences \& Research \\ Centre, Davangere, Karnataka, India \\ ${ }^{2}$ Post Graduate, Department of General Medicine, S.S. Institute of Medical Sciences \& Research Centre, \\ Davangere, Karnataka, India \\ Corresponding Author \\ Dr Savesh Roshan
}

Post Graduate, Department of General Medicine, S.S. Institute of Medical Sciences \& Research Centre,

Davangere, Karnataka, India

\begin{abstract}
Background: Diabetic cardiomyopathy is a well-known cardiovascular disorder. This study was aimed to evaluate diastolic function in patients with type 2 diabetes mellitus without cardiovascular risk factors based on echocardiographic findings.

Material: One year hospital based cross-sectional study. A total of 100 patients with type 2 diabetes mellitus for a period of one year were enrolled. All the patients underwent $2 D$ echocardiography and were evaluated for diastolic dysfunction.

Observations: 58\% patients were males and male to female ratio was 1.38:1. The common age group in this study was $>60$ years (43\%) and the mean age was $55.67+-11.13$ years. In $41 \%$ of the patients the duration of diabetes was between 1-5 years. $57 \%$ of the patients had uncontrolled diabetes with HbAlc of $>8 \%$. Diastolic dysfunction was present in $36 \%$ of the patients. Significant association of diastolic dysfunction was noted with age $(p=0.012)$ and duration of diabetes $(p=0.022)$ but no association was found with sex $(p=0.118)$, body mass index $(p=0.419)$ and glycemic control $(p=0.433)$.

Conclusion: Diastolic dysfunction is widely prevalent in patients with type 2 diabetes mellitus even in the absence of cardiovascular risk factors. Increased age and duration are the significant risk factors for diastolic dysfunction in patients with type 2 diabetes mellitus.

Keywords: Diabetes mellitus; Diabetic cardiomyopathy; Diastolic dysfunction.
\end{abstract}

\section{Introduction}

Diabetes mellitus (DM) is a heterogeneous group of metabolic disorders characterized by chronic hyperglycemia with disturbance of carbohydrate, fat and protein metabolism. It results from defects in insulin secretion, insulin action or both. The effect of diabetes mellitus include long term damage, dysfunction and failure of various organs, eyes, kidneys, nerves and heart and blood vessels. Several distinct types of DM are caused by complex interaction of genetics and environmental factors. ${ }^{1}$ Type 2 diabetes mellitus is 
metabolic and endocrinological disease characterized by hyperglycemia associated with insulin resistance and/or defective insulin secretion. $^{2}$

The persistence of these metabolic disturbances lead to permanent and irreversible functional and structural changes in the cells of the body which in turn lead to the development of "diabetic complications", characteristically affecting, the cardiovascular system, eye, kidney and nervous system mainly. ${ }^{3}$

Risks of incidence from CAD or fatal CAD are two- to fourfold higher in people with DM than in those without. Furthermore, long-term prognosis after a coronary event is significantly worse among people with DM than those without. ${ }^{4}$

Accordingly, the National Cholesterol Education Program (NCEP) guidelines classify DM as a CAD "risk equivalent" - a disorder that carries an absolute, 10-year risk for developing new major coronary events equal to that of non-diabetic persons with established CAD (i.e., less than 20\%). However, the core metabolic defect in DM (i.e., hyperglycemia) does not by itself raise the risk to the level of a CAD risk equivalent - it is a constellation of metabolic risk factors that combine with hyperglycemia to impart a high risk. $^{5}$

Diastolic heart failure (HF) is also referred to as HF, with preserved left ventricular systolic function. Many studies have reported that the incidence of heart failure in diabetic subjects is high even in the absence of hypertension and coronary artery disease. Studies have reported a high prevalence of pre-clinical diastolic dysfunction among subjects with DM. ${ }^{6}$ The evidence indicates that myocardial damage in diabetic subjects affects diastolic function before the systolic function. Diabetic cardiomyopathy has been proposed as an independent cardiovascular disease, and many mechanisms, such as microvascular disease, autonomic dysfunction, metabolic disorders, and interstitial fibrosis, have been suggested as causative factors. ${ }^{7}$
Hence this study was planned to determine whether there is any association between diastolic dysfunction and type 2DM in the asymptomatic subjects.

\section{Objectives}

- To evaluate diastolic function in patients with type $2 \mathrm{DM}$ without cardiovascular risk factors based on echocardiographic findings.

\section{Materials and Methods}

This study was done in the Department of Medicine, S. S. Institute of Medical Sciences and Research Centre, Davangere, Karnataka. The study design was a hospital based cross-sectional study. The present study was conducted for the period of one year.

\section{Source of Data}

Patients with history of type 2 diabetes mellitus as per ADA guidelines attending Out Patient Department of Medicine and admitted in the Wards of Medicine at S. S. Institute of Medical Sciences and Research Centre, Davanagere were enrolled.

\section{Sample Size}

A total of 100 patients with type 2 diabetes mellitus as per ADA guidelines were included.

\section{Selection Criteria}

Patients of both the sex aged above 30 years, with type 2 diabetes mellitus and blood pressure $<130 / 80 \mathrm{mmHg}$ with normal ECG were included in the study.

Patients with type diabetes mellitus with Evidence of coronary artery disease, Valvular heart diseases, cardiomyopathies, Hypertensive patients, patients with Systolic dysfunction, Dyslipidemia, Overweight and obesity (BMI > 25 $\mathrm{Kg} / \mathrm{m} 2$ ) were excluded from the study.

\section{Data collection}

Patients were interviewed and demographic data such as age and sex were noted. Further they were subjected to thorough clinical examination and systemic examination where patients were evaluated for the vitals and clinical signs. These 
findings were recorded on a predesigned and pretested proforma.

\section{Investigations}

All the patients were subjected to random blood sugar, fasting blood sugar, HbA1c, Serum creatinine, Lipid profile, Fundoscopy, Electrocardiogram, 2D echocardiography investigations.

\section{Outcome variables}

All the patients were evaluated for diastolic function. The diastolic function was evaluated using M Mode and Two dimensional transthoracic echocardiography and color flow Doppler examination.

\section{Statistical analysis}

The data obtained was coded and entered into Microsoft Excel Worksheet (Annexure III). The data was analyzed using SPSS statistical software version 20.0. The categorical data was expressed in terms of percentage and ratios and comparison was done using either Chi-square test or Fisher's exact test. The continuous data was expressed as mean \pm standard deviation (SD) and comparison was done using independent sample ' $t$ 'test. A probability value ('p' value) of $\leq 0.05$ at $95 \%$ CI was considered as statistically significant.

\section{Results}

In the present study $58 \%$ of the patients were males and $42 \%$ were females. The male to female ratio was 1.38:1.

Table 1. Age distribution

\begin{tabular}{lcc}
\hline \multirow{2}{*}{ Age group (Years) } & \multicolumn{2}{c}{ Distribution $(\mathrm{n}=100)$} \\
& Number & Percentage \\
\hline 31 to 40 & 13 & 13.00 \\
41 to 50 & 22 & 22.00 \\
51 to 60 & 22 & 22.00 \\
$>60$ & 43 & 43.00 \\
Total & 100 & 100.00 \\
\hline
\end{tabular}

In this study the commonest age group was $>60$ years $(43 \%)$ followed by 51 to 60 years and 41 to 50 years (22\% each).
Table 2. Duration of diabetes

\begin{tabular}{|c|c|c|}
\hline \multirow{2}{*}{$\begin{array}{l}\text { Duration } \\
\text { (Years) }\end{array}$} & \multicolumn{2}{|c|}{ Distribution $(n=100)$} \\
\hline & Number & Percentage \\
\hline$\leq 1$ & 29 & 29.00 \\
\hline$>1$ to 5 & 41 & 41.00 \\
\hline 6 to 10 & 19 & 19.00 \\
\hline$>10$ & 11 & 11.00 \\
\hline Total & 100 & 100.00 \\
\hline
\end{tabular}

In the present study most of the patients (41\%) had duration of diabetes between $>1$ year to five years followed by $\leq 1$ year (29\%).

In this study majority of the patients $(72 \%)$ had body mass index between 18.5 to $22.99 \mathrm{Kg} / \mathrm{m} 2$ while $28 \%$ of the patients had body mass index between 23.00 to $24.99 \mathrm{Kg} / \mathrm{m} 2$.

In this study the fasting blood sugar levels were raised (>126 mg/dL) in $83 \%$ of the patients.

In the present study HbAlc levels were $>8$ percent in $57 \%$ of the patients while $38 \%$ of the patients had $\mathrm{HbA} 1 \mathrm{c}$ levels between 7 to 8 percent.

Table 3 Clinical, diabetic and lipid profile of the patients

\begin{tabular}{lcc}
\hline \multirow{2}{*}{ Variables } & \multicolumn{2}{c}{ Mean } \\
\hline Age (Years) & 55.67 & 11.13 \\
Duration (Years) & 45.11 & 25.53 \\
Pulse rate (/Minute) & 75.06 & 5.65 \\
Respiratory rate (/Min) & 15.07 & 1.16 \\
Systolic blood pressure (mm Hg) & 124.22 & 7.85 \\
Diastolic blood pressure (mm Hg) & 77.88 & 4.86 \\
Body mass index (Kg/m2) & 21.99 & 1.27 \\
Random blood sugar (mg/dL) & 213.11 & 66.04 \\
Fasting blood sugar (mg/dL) & 147.58 & 39.89 \\
HbA1c (\%) & 8.36 & 1.22 \\
Cholesterol (mg/dL) & 149.37 & 8.82 \\
Low density lipoprotein (mg/dL) & 118.09 & 8.92 \\
High density lipoprotein (mg/dL) & 51.06 & 3.90 \\
Triglycerides (mg/dL) & 141.97 & 6.80 \\
Urea (mg/dL) & 27.15 & 6.50 \\
Serum creatinine (mg/dL) & 0.78 & 0.16 \\
\hline
\end{tabular}




\section{Graph 1. Diastolic dysfunction}

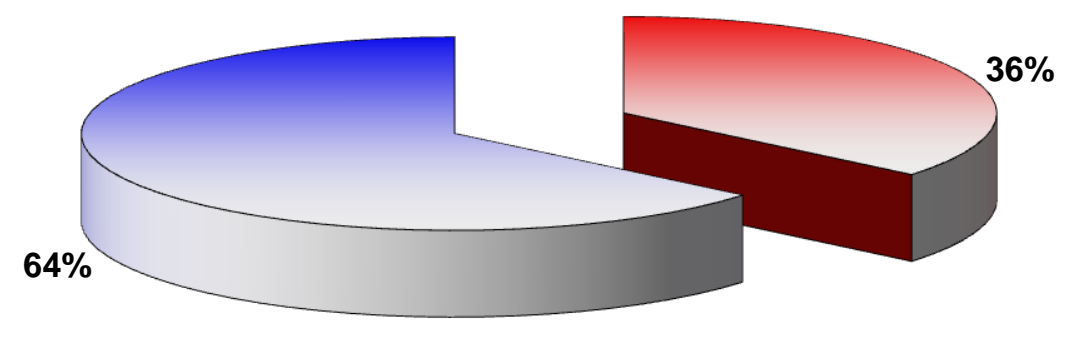

口Present $\square$ Absent

In this study diastolic dysfunction was present in $36 \%$ of the patients.

In the present study diastolic dysfunction was noted in $41.38 \%$ of the males compared to $28.57 \%$ of the females. but the difference was statistically not significant $(\mathrm{p}=0.188)$

In this study the incidence of diastolic dysfunction was high in patients with age $>60$ years $(53.49 \%)$ compared to diabetic patients who were aged between 51 to 60 years $(31.82 \%), 41$ to 50 years $(18.18 \%)$ and 31 to 40 years $(15.38 \%)(\mathrm{p}=0.012)$. In the present study diastolic dysfunction was significantly high in patients who reported duration of diabetes between 6 to 10 years $(88.89 \%)$ compared to those with duration between $>1$ to 5 years $(46.34 \%)$ and $\leq 1$ year $(13.79 \%)(\mathrm{p}=0.022)$.

In this study diastolic dysfunction was almost comparable in patients with normal body mass index $(34.72 \%)$ and those who were at risk of obesity $(39.29 \%)(p=0.419)$

In this study the frequency of diastolic dysfunction was comparable in patients with HbA1c <7 (40\%), between 7 to $8(31.58 \%)$ and > 8 percent $(38.60 \%)(\mathrm{p}=0.433)$

Table 4. Association of diastolic dysfunction with diabetic control

\begin{tabular}{|c|c|c|c|c|}
\hline \multirow{3}{*}{ HbA1c (\%) } & \multicolumn{4}{|c|}{ Diastolic dysfunction } \\
\hline & \multicolumn{2}{|c|}{ Present } & \multicolumn{2}{|c|}{ Absent } \\
\hline & Number & Percentage & Number & Percentage \\
\hline$<7$ & 2 & 40.00 & 3 & 60.00 \\
\hline 7 to 8 & 12 & 31.58 & 26 & 68.42 \\
\hline$>8$ & 22 & 38.60 & 35 & 61.40 \\
\hline Total & 36 & 36.00 & 64 & 64.00 \\
\hline
\end{tabular}

Table 5 shows comparison of clinical, diabetic and lipid profile of the patients with and without diastolic dysfunction. It was observed that, patients with diastolic dysfunction had significantly higher age $(\mathrm{p}=0.004)$ and duration of type 2 diabetes mellitus ( $\mathrm{p}=0.005)$. 
Table 5. Comparison of clinical, diabetic and lipid profile in patients with and without diastolic dysfunction

\begin{tabular}{lccccc}
\hline \multirow{2}{*}{ Variables } & \multicolumn{3}{c}{ Diastolic dysfunction } & \\
& \multicolumn{2}{c}{ Present } & \multicolumn{2}{c}{ Absent } & p value \\
& Mean & SD & Mean & SD & \\
\hline Age (Years) & 59.69 & 9.10 & 53.41 & 11.58 & 0.004 \\
Duration (Years) & 53.98 & 20.60 & 40.13 & 26.81 & 0.005 \\
Pulse rate (/Minute) & 74.17 & 5.52 & 75.56 & 5.71 & 0.234 \\
Respiratory rate (/Min) & 15.22 & 1.10 & 14.98 & 1.19 & 0.316 \\
Systolic blood pressure (mm Hg) & 124.39 & 7.82 & 124.13 & 7.92 & 0.872 \\
Diastolic blood pressure (mm Hg) & 79.06 & 5.71 & 77.22 & 4.21 & 0.097 \\
Body mass index (Kg/m2) & 22.17 & 1.30 & 22.03 & 1.48 & 0.636 \\
Random blood sugar (mg/dL) & 217.28 & 67.84 & 210.77 & 65.43 & 0.642 \\
Fasting blood sugar (mg/dL) & 144.03 & 42.62 & 149.58 & 38.47 & 0.520 \\
HbA1c (\%) & 8.29 & 1.07 & 8.40 & 1.30 & 0.641 \\
Cholesterol (mg/dL) & 147.50 & 9.94 & 150.42 & 8.02 & 0.137 \\
Low density lipoprotein (mg/dL) & 117.44 & 8.51 & 118.45 & 9.18 & 0.582 \\
High density lipoprotein (mg/dL) & 45.83 & 8.69 & 48.00 & 8.12 & 0.225 \\
Triglycerides (mg/dL) & 149.08 & 7.17 & 149.55 & 8.61 & 0.774 \\
Urea (mg/dL) & 27.03 & 6.53 & 27.22 & 6.53 & 0.889 \\
Creatinine (mg/dL) & 0.79 & 0.16 & 0.78 & 0.15 & 0.674 \\
\hline
\end{tabular}

\section{Discussion}

Diabetes mellitus is a group of common metabolic disorders that share the phenotype of hyperglycemia and associated with a multitude of cardiovascular complications. Clinical, epidemiological and pathological studies reveal the increased occurrence of clinical congestive heart failure in patients with diabetic patients to diabetic cardiomyopathy as determined by diastolic and/or systolic left ventricular dysfunction. ${ }^{9}$

Left ventricular diastolic dysfunction represents the reversible first stage of diabetic cardiomyopathy 2 which reinforces the importance of evaluation for early examination of diastolic ventricular function in patients with diabetes mellitus. Even in diabetic patients, the risk of heart failure is increased without the clinical evidence of CAD. Myocardial involvement in diabetes mellitus may occur early in the course of disease which impairs early diastolic relaxation initially and causes decreased myocardial contraction when becomes more extensive. Prior to the development of symptomatic congestive heart failure, sub-clinical left ventricular dysfunction (systolic or diastolic) exists for sometime. ${ }^{9}$

However, to-date, limited number of studies88-94 have reported the frequency of progression from pre-clinical to clinically evident myocardial dysfunction in patients with diabetes mellitus. With the availability of echocardiography and Doppler, the natural history of cardiac involvement from pre-clinical to clinical stage in patients with diabetes can be elucidated. This prompted us to evaluate diastolic function in patients with type 2 DM without having cardiovascular risk factors based on echocardiographic findings.

The present one year hospital based crosssectional study was performed in the settings of Department of Medicine, S. S. Institute of Medical Sciences and Research Centre, Davangere, Karnataka from January 2014 to December 2014. A total of 100 patients who were diagnosed to have type 2 diabetes mellitus based on ADA guidelines8 were enrolled. All the patients were subjected to the 2D echocardiography for the assessment of diastolic dysfunction. 
It is reported that, the prevalence of diabetes is higher in men than women. ${ }^{10-17}$ Same was true in the present study as most of the patients were males (58\%) and male to female ratio was 1.38:1. These findings suggest higher prevalence of diabetes among males in this study which was consistent with the previous literature.

Unlike in the West, where older persons are most affected, diabetes in Asian countries is disproportionately high in young to middle-aged adults. In the present study $43 \%$ of the patients were aged $>60$ years and the next common age group was 51 to 60 years and 41 to 50 years which were comprised of $22 \%$ of the patients each. Based on the selection criteria being type 2 diabetes mellitus patients aged over 30 years, the youngest patients was aged 34 years and oldest patient was aged 84 years. The mean age was $55.67 \pm 11.13$ years. These findings show that, diabetes mellitus was widely prevalent among elderly. The higher prevalence of diabetes among aged can be explained by the rise in the segment of geriatric population.

In the present study random and fasting blood sugar levels (> $130 \mathrm{mg} / \mathrm{dL}$ and $>110 \mathrm{mg} / \mathrm{dL}$ respectively) in $97 \%$ and $83 \%$ of the patients. Also HbA1c levels revealed $57 \%$ of the patients with $>8$ percent and $38 \%$ of the patients with HbA1c levels between 7 to 8 percent. The mean fasting, random blood sugar and HbA1c levels were $147.58 \pm 39.89 \mathrm{mg} / \mathrm{dL}, 213.11 \pm 66.04$ $\mathrm{mg} / \mathrm{dL}$ and $8.36 \pm 1.22$ percent. These findings suggest that, majority of the patients in this study had poor glycemic control.

It is suggested that diabetes can affect cardiac structure and function in the absence of changes in blood pressure or coronary artery disease, a condition called diabetic cardiomyopathy. ${ }^{17}$ Cardiovascular complications are known to be the main cause of death and morbidity in diabetic patients, as over $75 \%$ of all diabetic patients die from cardiovascular events. There is an increased rate of ischemic heart disease and cardiomyopathy, which may lead to congestive heart failure in the absence of coronary atherosclerosis. Heart failure is a common and serious co-morbidity of diabetes. ${ }^{18}$ The Framingham study ${ }^{19}$ demonstrated an increased risk in heart failure in patients with diabetes and that it has a greater impact on the incidence of congestive heart failure, especially in women. It has been shown a 2-fold higher incidence of heart failure in men with diabetes and a 5-fold increase in women. Additional trials, Studies of Left Ventricular Dysfunction (SOLVD), the Heart Outcomes Prevention Evaluation study (HOPE), the Cardiovascular Health Study (CHS) and nationwide case-control study - also identified diabetes as a major risk factor for the development of heart failure. ${ }^{20-22}$ Recently a study of health maintenance organization in nearly 10,000 type 2 diabetic patients, $12 \%$ had heart failure at entry and about $3.3 \%$ of type 2 diabetic subjects developed heart failure each year.23 LVDD is considered the earliest manifestation of diabetic cardiomyopathy, preceding the development of systolic dysfunction. In the present study based $36 \%$ of the patients had diastolic dysfunction.

Several studies have reported diastolic dysfunction in patients with diabetes mellitus. The reported range of diastolic dysfunction in patients with diabetes mellitus ranges between $40 \%$ to as high as $75 \%$. Recently Dixit NM. et al. ${ }^{9}$ (2013) in their case control study from Surat, India reported prevalence of diastolic dysfunction in as high as $66 \%$ of the patients with normotensive diabetic patients. Similar rate of Diastolic dysfunction was reported by Patiland Burji ${ }^{24}$ in 2012 from Mysore, Karnataka where $64 \%$ of the subjects with type 2 diabetes mellitus had diastolic dysfunction. Patil VC. et al. ${ }^{14}$ in their case control study from during 2011 at Satara, Maharashtra reported $54.33 \%$ of subjects with type $2 \mathrm{DM}$ had diastolic dysfunction. Poulsen MK. et al. ${ }^{25}$ in 2009 found incidence of LV diastolic dysfunction in $40 \%$ of the patients with T2DM with no history of cardiovascular disease. A study by Shreshta et al. $^{26}$ in 100 asymptomatic type 2 Diabetes Mellitus, LVDD was found in 71 subjects. Soldatos et al. ${ }^{27}$ in their case control study of 55 
individuals with type-2 DM reported presence of DD in a significant proportion of population with Type 2 DM. Boyer et al.28 stated that the prevalence of $\mathrm{LV}$ diastolic dysfunction in asymptomatic, normotensive patients with type 2 diabetes disease is high. Diastolic dysfunction was found in $75 \%$ subjects. Exiara et al. ${ }^{29}$ in their study of 114 subjects reported $63.2 \%$ patients with diastolic dysfunction in their study compared to our prevalence of $36 \%$.

The frequency of diastolic dysfunction observed in the present study was comparable with a study done by Poulsen MK. et al. ${ }^{25}$ who reported diastolic dysfunction in $40 \%$ of the patients with T2DM. The frequency of diastolic dysfunction observed in the present study that is, $36 \%$ was low compared to the previous studies due to careful selection of patients with type 2 diabetes mellitus excluding cardiovascular risk factors like smoking, consumption of tobacco products, overweight and obesity, dyslipidaemia and hypertension. Majority of the patients in this study (72\%) had body mass index between 18.5 to 22.99 $\mathrm{Kg} / \mathrm{m} 2$ while $28 \%$ of the patients had body mass index between 23.00 to $24.99 \mathrm{Kg} / \mathrm{m} 2$. Further the frequency of diastolic dysfunction was almost comparable in patients with normal body mass index $(34.72 \%)$ and those who were at risk of obesity $(39.29 \%) \quad(\mathrm{p}=0.419)$. Epidemiological studies ${ }^{30-34}$ have associated diastolic function with aging, hypertension and myocardial ischemia. Besides, more recent data have also demonstrated an independent association between diastolic function and obesity, ${ }^{32}$ especially with abdominal obesity $^{33}$ and visceral fat mass.34We presume that if these risk factors are considered the rate diastolic dysfunction could be very high.

In this study the rate of diastolic dysfunction was significantly high in elderly patients (age > 60 years). It was observed that, $53.49 \%$ of the patients with age $>60$ years had diastolic dysfunction which reduced with decline in age that is, $31.82 \%$ of the patients with age between 51 to 60 years, $18.18 \%$ aged between 41 to 50 years and least that is $15.38 \%$ of the patients in 31 to 40 years $(\mathrm{p}=0.012)$. Further the mean age was significantly high in patients who had diastolic dysfunction $(59.69 \pm 9.10$ years vs $53.41 \pm 11.58$ years; $\mathrm{p}=0.004)$. These findings were consistent with previous reports by Mishra et al. ${ }^{35}$ and Patil VC. et al. ${ }^{36}$ Patil and Burji36 also reported linear progression of diastolic dysfunction with the increase age group. Exiaraet al.29 in their study of 114 subjects also stated that the prevalence of LV diastolic dysfunction in normotensive, asymptomatic and well-controlled DM type 2 patients is high, and increases with age.

In the present study $41 \%$ of the patients had duration of diabetes between $>1$ year to five years. Diastolic dysfunction was significantly high in patients who reported duration of diabetes between 6 to 10 years $(88.89 \%)$ compared patients having duration between more than one year to five years (46.64\%) and less than or equal to one year $(13.79 \%) \quad(p=0.022)$. Further the mean duration was significantly high in patients with diastolic dysfunction $(5.66 \pm 4.13$ years vs $3.87 \pm$ 4.04 years; $p=0.040$ ). Similar observations were reported in other studies by Patil and Burji,36 Mishra et al., ${ }^{35}$ From et al.37 and Patil VC et al. ${ }^{36}$ Mishra et al. ${ }^{35}$ in their case control study of 71 subjects with type $2 \mathrm{DM}$ found that asymptomatic diabetic patients have reduced LV systolic and diastolic function as compared with healthy subjects. LV systolic and diastolic abnormalities correlated with the duration of diabetes. From et al. ${ }^{37}$ in their study of 484 subjects between 1996 to 2007 year found that a duration of diabetes $\geq 4$ years was independently associated with LV diastolic dysfunction $\left(E / e^{\prime}>15\right)$ with odds ratio 1.91.

In the present study no statistically significant association was found between diastolic dysfunction and sex as $41.38 \%$ of the males and $28.57 \%$ of the females had diastolic dysfunction ( $\mathrm{p}=0.188$ ). In contrast to these observations Patil $\mathrm{MB}$ and Burji $\mathrm{NP}^{36}$ reported that diastolic dysfunction is more common among female sex $(68.18 \%)$ compared to male $(60.17 \%)$. 
In this study no association was found between diastolic dysfunction and glycemic control. The frequency of diastolic dysfunction was comparable in patients with HbA1c $<7(40 \%)$, between 7 to $8(31.58 \%)$ and $>8$ percent $(38.60 \%)$ $(\mathrm{p}=0.433)$. However in contrast to our findings, Patil MB and Burji $\mathrm{NP}^{36}$ reported that, diastolic dysfunction was significantly associated with uncontrolled diabetes as assessed by $\mathrm{HbA1c}$ levels.

Overall this study demonstrates that the incidence of diastolic dysfunction in patients with type 2 $\mathrm{DM}$ is high. Also there is a direct relation between age of the patients and diastolic dysfunction. However, since this study was hospital based study and included patients from single centre, the rate of diastolic dysfunction cannot be generalized and needs further evaluation.

\section{Conclusion}

Heart failure is one of the common manifestations in patients with type 2 diabetes mellitus and diastolic dysfunction represents early stages of heart failure. From the findings of this study it may concluded that, a considerable subset of patients with type 2 diabetes mellitus are likely to have diastolic dysfunction as more than two thirds of the selected population had diastolic dysfunction. Furthermore, increased age and duration are the significant the risk factors for diastolic dysfunction in patients with type 2 diabetes mellitus.

\section{References}

1. Fauci AS, Kasper DS, Longo DL, Braunwald E, Hauser SL, Jameson JL, et al. Harrison's principles of internal medicine. United States; McGraw Hill: 2015.

2. Sarkar A, Dash S, Barik BK, Muttigi MS, Kedage V, Shetty JK, et al. Copper and Ceruloplasmin levels in relation to total thiols and GST in type 2 diabetes mellitus patients. Ind J ClinBiochem 2010;25:74-6.
3. Koda-Kimble MA, Carlisle BA. Diabetes mellitus. In: Young LY, Koda-Kimble MA, Kradjan WA, Guglielmo BJ, eds. Applied therapeutics: the clinical use of drugs. 6th ed., Vancouver (WA): Applied therapeutics 1995; 48:481-5.

4. Kalofoutis C, Piperi C, Kalofoutis A, Harris F, Phoenix D, Singh J. Type II diabetes mellitus and cardiovascular risk factors: Current therapeutic approaches. ExpClinCardiol 2007;12(1):17-28.

5. National Cholesterol Education Program (NCEP) Expert Panel on Detection, Evaluation, and Treatment of High Blood Cholesterol in Adults (Adult Treatment Panel III) Third Report of the National Cholesterol Education Program (NCEP) Expert Panel on Detection, Evaluation, and Treatment of High Blood Cholesterol in Adults (Adult Treatment Panel III) final report. Circulation 2002;106:3143-421.

6. Kazik A, Wilczek K, Poloński L. Management of diastolic heart failure. Cardiol J 2010;17:558-65.

7. From AM, Scott CG, Chen HH. Changes in diastolic dysfunction in diabetes mellitus over time. Am J Cardiol 2009;103:1463-6.

8. Executive summary: Standards of medical care in diabetes-2011. Diabetes Care 2011;34:S4-10.

9. Dikshit NM, Wadia PZ, Shukla DK. Diastolic dysfunction in Diabetes Mellitus. Natl J Med Res 2013;3(3):249-52.

10. Swain RP, Subudhi BB, Mahapatra AK, Bolapreddi V. Bridging Between Disease, Prevalence and Treatment of Diabetes Mellitus: A Review. Int J Pharm Tech Res 2015;7(2):212-28.

11. Kopelman PG, Hitman GA. Naturally occurring antihyper glycemic and antidyslipedimic agents. The Lancet 1998;5:352. 
12. Shi Y, Frank B. The global implications of diabetes and cancer. The Lancet 1947;9933:383.

13. Henry M, Kronenberg MD, Shlomo Melmed MD, Kenneth S. Polonsky MD. 'Williams's textbook of endocrinology. 12th ed., Philadelphia: Elsevier/ Saunders; 2011.

14. Vos T, Flaxman AD, Nghavi M, Lozano R, Michaud C, Ezzati M, et al. A systemic analysis for the global burden of disease study, The Lancet 2010;380 (9859):2163.

15. Mathers CD, Loncar D. Projections of global mortality and burden of disease from 2002 to 2030. PLOS Med 2006;3(11):442.

16. Shaw JE, Sicree RA, Zimmet PZ. Global estimates of the prevalence of diabetes for 2010 and 2030. Diabetes Res ClinPract 2010;87:4-14.

17. Boudina S, Dale Abel E. Diabetic cardiomyopathy revisited. Circulation 2007;115:3213-23.

18. Freire CM, Moura AL, Barbosa Mde M, Machado LJ, Nogueira AI, RibeiroOliveira A. Left ventricle diastolic dysfunction in diabetes: an update. Arq Bras EndocrinolMetabol 2007;51(2):16875.

19. Kannel WB, Mc Gee DL. Diabetes and cardiovascular disease. The Framingham study. JAMA 1979;241(19):2035-8.

20. Shindler DM, Kostis JB, Yusuf S, Quinones MA, Pitt B, Stewart D, et al. Diabetes mellitus, a predictor of morbidity and mortality in the Studies of Left Ventricular Dysfunction (SOLVD) Trials and Registry. Am J Cardiol 1996;77(11):1017-20.

21. Piccini JP, Klein L, Gheorghiade M, Bonow RO. New insights into diastolic heart failure: role of diabetes mellitus. Am J Med 2004;116(suppl 5A):64S-75.

22. Bertoni AG, Tsai A, Kasper EK, Brancati FL. Diabetes and idiopathic cardiomyopathy: a nationwide case-control study. Diabetes Care 2003; 26(10):2791-5.

23. Nichols GA, Hillier TA, Erbey JR, Brown JB. Congestive heart failure in type 2 diabetes: prevalence, incidence, and risk factors. Diabetes Care 2001; 24(9):1614-9.

24. Patil MB, Burji NA. Echocardiographic Evaluation of Diastolic Dysfunction in Asymptomatic Type 2 Diabetes Mellitus. JAPI 2012;60:23-6.

25. Poulsen MK, Henriksen JE, Dahl J, Johansen A, Gerke O, Vach W, et al. Left Ventricular Diastolic Function in Type 2 Diabetes Mellitus: Prevalence and Association With Myocardial and Vascular Disease; Circ Cardiovasc Imaging 2010;3:24-31.

26. Shrestha NR, Sharma SK, Karki P, Shrestha NK, Acharya P. Echocardigraphic evaluation of diastolic function in asymptomatic type 2 diabetes. J Nepal Assoc 2009;48(173):20-3.

27. Soldatos G, Jandeleit-Dahm K, Thomson H, Formosa M, D'orsa K, Calkin AC, et al. Large artery biomechanics and diastolic dysfunctionin patients with Type 2 diabetes. Diabet Med 2011;28:54-60.

28. Boyer JK, Thanigaraj S, Schechtman KB, Pérez JE. Prevalence of ventricular diastolic dysfunction in asymptomatic, normotensive patients with diabetes mellitus. Am J Cardiol2004;93:870-5.

29. Exiara T, Konstantis A, Papazoglou L, Kouroupi M, Kalpaka A, Mporgi L, et al. Left ventricular diastolic dysfunction in diabetes mellitus Type 2. J Hypertens 2010;28:e294.

30. Fontes-Carvalho R, Ladeiras-Lopes R, Bettencourt P, Leite-Moreira A, Azevedo A. Diastolic dysfunction in the diabetic continuum: association with insulin resistance, metabolic syndrome and type 2 diabetes. CardiovascDiabetol 2015;14:4.

31. Redfield MM, Jacobsen SJ, Burnett JC, Jr, Mahoney DW, Bailey KR, Rodeheffer RJ. 
Burden of systolic and diastolic ventricular dysfunction in the community: appreciating the scope of the heart failure epidemic. JAMA 2003;289:194-202.

32. Russo C, Jin Z, Homma S, Rundek T, Elkind MS, Sacco RL, et al. Effect of obesity and overweight on left ventricular diastolic function: a community-based study in an elderly cohort. J Am CollCardiol2011;57:1368-74.

33. Canepa M, Strait JB, Abramov D, Milaneschi Y, AlGhatrif M, Moni M, et al. Contribution of central adiposity to left ventricular diastolic function (from the Baltimore Longitudinal Study of Aging) Am J Cardiol2012;109:1171-8.

34. Canepa M, Strait JB, Milaneschi Y, Alghatrif M, Ramachandran R, Makrogiannis S, et al. The relationship between visceral adiposity and left ventricular diastolic function: Results from the Baltimore Longitudinal Study of Aging. NutrMetabCardiovasc Dis 2013;23:1263-70.

35. Mishra TK, Rath PK, Mohanty NK, Mishra SK. Left ventricular systolic and diastolic dysfunction and their relationship with microvascular complications in normotensive, asymptomatic patients with type 2 diabetes mellitus. Indian Heart $\mathbf{J}$ 2008;60:548-53.

36. Patil VC, Patil HV, Shah KB, Vasani JD, Shetty P. Diastolic dysfunction in asymptomatic type 2 diabetes mellitus with normal systolic function. $\mathrm{J}$ Cardiovasc Dis Res 2011;2(4):213-22.

37. From AM, Scott CG, Chen HH. The development of heart failure in patients with diabetes mellitus and pre-clinical diastolic dysfunction. J Am CollCardiol2010;55:300-5. 